\title{
Association between the accessory gene regulator (agr) locus and the presence of superantigen genes in clinical isolates of methicillin-resistant Staphylococcus aureus
}

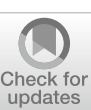

Hamed Tahmasebi ${ }^{1}$, Sanaz Dehbashi ${ }^{2}$ and Mohammad Reza Arabestani $i^{3,4^{*}}$

\begin{abstract}
Objective: Methicillin-resistant Staphylococcus aureus cause to a variety of hard to cure infections. MRSA isolates also, produce an arsenal of virulence factors contribute to severe infections. The aim of this study was to find out the relationship between agr locus and presence of S. aureus superantigens (SAgs).

Results: Clinical isolates in two groups from two different states of Iran were collected. Antibiotic resistance patterns, agr typing, and virulence factor genes prevalence were identified and relationship between them was analyzed using SPSS software version16. Most of the samples were collected from wound 39 isolates in Group 1 and 61 isolates in Group 2. Frequency of MRSA strains was 38.1\% in Group 1 and 52.1\% in Group 2. Also, the most common resistance among both groups was to penicillin. agr positive isolates were detected in 132 isolates of Group 1 and 104 isolates of Group 2. In Conclusion, a significant relationship between the SAgs frequency and agr locus in both groups has been indicated. The production of superantigens in S. aureus plays an important role in the classification of agr locus, and this locus can affect differently in methicillin-resistant strains.
\end{abstract}

Keywords: Methicillin-resistant Staphylococcus aureus, Superantigens, Virulence factors, agr locus

\section{Introduction}

Inappropriate use of antibiotics to treat $S$. aureus infections have led to the development of antibiotic resistant strains. The first cases of methicillin-resistant $S$. aureus (MRSA) were identified in the 1960 s, shortly after its introduction into clinical practice $[1,2]$. Methicillin resistance is conferred by the $m e c A$ gene, which encodes a novel penicillin binding protein (PBP2A) [3, 4]. This protein has a reduced affinity for $\beta$-lactam antibiotics. The mecA gene is carried on a mobile genetic element known as the Staphylococcal Cassette Chromosome mec (SCCmec), which can be horizontally transferred between Staphylococcal strains [5].

\footnotetext{
*Correspondence: mohammad.arabestani@gmail.com

${ }^{3}$ Department of Microbiology, School of Medicine, University of Hamadan, Hamadan, Iran

Full list of author information is available at the end of the article
}

Staphylococcus aureus encodes toxin and superantigens like hemolysins, enterotoxins, exotoxins, exfoloative toxins, toxic shock syndrome toxin-1 (TSST-1) and leukotoxins such as the Panton-Valentine leukocidin (PVL). Different $S$. aureus strains encode different toxins. Exfoliative toxins, TSST-1 and PVL are presented only in some clones [6]. Reduced toxicity can hide the bacteria from the immune system, therefore, facilitate more stable and successful colonization in the host [7]. However, there are a number of undescribed genes in the MRSA strains, which encode virulence factors associated with infections in animals and human. Global regulators such as the accessory gene regulator (agr) system, Staphylococcal accessory regulator (Sar) and S. aureus exoprotein expression (Sae), have been well characterized which could help bacteria to adapt to a hostile environment $[8,9]$.

The production of $S$. aureus virulence factors is directly related to methicillin resistance. The $m e c A$ gene indirectly activates Autoinducer peptides (AIPs), which 
play an important role in the production of some regulatory factors, biofilms and quorum-sensing (QS) [9]. Beceiro et al. state that methicillin resistance induces cell wall alterations that affect the agr quorum-sensing system of the bacteria and consequently reduced virulence in a murine model of sepsis $[9,10]$.

In this research, MRSA and non-MRSA strains were examined with the aim of investigating the relationship between $a g r$ regulatory system and virulence factors.

\section{Main text \\ Methods \\ Isolation and identification of S. aureus}

This cross-sectional study was designed to measure the prevalence of methicillin-resistant Staphylococcus aureus among patients and healthcare workers (three hospitals, four clinical laboratories, and two healthcare centers) in Hamadan (Group 1) and Sistan and Baluchistan (Group 2) during July 2015 and August 2016. A multistage sampling method was used to select areas with different climate. Based on the distribution patterns of antibiotic resistance and different characteristics of the 28 states, the two states with the most differences in climate were selected. Sampling was done by considering the temperature variation index in different seasons and analyzing this index. Clinical specimens were inoculated on sheep blood agar (Merk, Darmstadt, Germany) and mannitol salt agar (Merk, Darmstadt, Germany), and incubated at $35-37{ }^{\circ} \mathrm{C}$ for 18 to $24 \mathrm{~h}$ aerobically. Biochemical tests were implicated to confirm the suspected isolates [11].

\section{Detection of MRSA and determination of antimicrobial susceptibility profile of each isolate}

Antimicrobial susceptibility testing was carried out by the Kirby Bauer disc diffusion method according to the Clinical Laboratory Standards Institute (CLSI) guidelines 2017 on Muller Hinton agar (Merk, Darmstadt, Germany). The following drugs were used to determine the antibiotic susceptibility: penicillin (10 U), tetracycline $(30 \mu \mathrm{g})$, clindamycin $(30 \mu \mathrm{g})$, gentamicin $(30 \mu \mathrm{g})$, ciprofloxacin $(5 \mu \mathrm{g})$, erythromycin $(15 \mu \mathrm{g})$, chloramphenicol $(30 \mu \mathrm{g})$, rifampin $(5 \mu \mathrm{g})$, trimethoprim-sulfamethoxazole $(10 \mu \mathrm{g})$ and linezolid $(30 \mu \mathrm{g})$. All antibiotic disks were obtained from MAST ${ }^{\circledR}$ Company, U K. Methicillin susceptibility was determined using the cefoxitin E-test (Liofilchem, Italy) and oxacillin E-test (AB BIODISK, Sweden). S. aureus ATCC25923 was used as negative control and S. aureus ATCC43300 was used as positive control.

\section{Genomic DNA extraction}

Genomic DNA was extracted by Cinnaclon DNA extraction kit (Cinnaclon, Iran) based on manufacturer's instruction. DNA was yielded and investigated by spectrophotometry using the Nanodrop (ThermoFishers, USA).

\section{PCR for superantigen genes and screening for strains}

The superantigen genes were amplified with specific primers listed by Schlievert and et al. [12] and Jarraud et al. [13] studies.

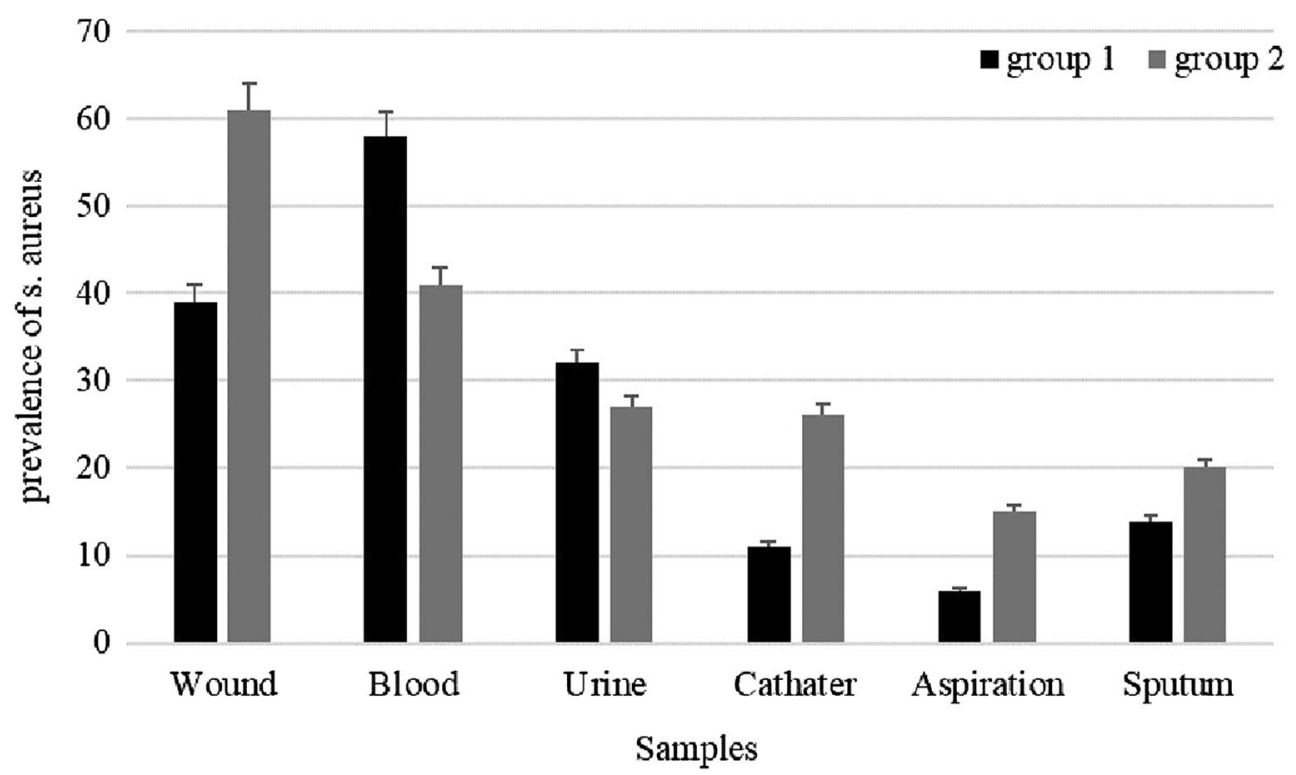

Fig. 1 Distribution of different samples between Group 1 and Group 2 Staphylococcus aureus 


\section{agr typing}

Classification of agr system groups was based on the hyper variable domain of agr locus according to Soares et al. [14]. Duplex PCR was performed to type groups based on their product size.

\section{Statistical analysis}

Data were organized and analyzed using the Statistical Package for Social Sciences (SPSS) software, version 16. The correlation between phenotypic antibiotic pattern and agr locus, phenotypic antibiotic pattern and superantigens genes, superantigens genes and $a g r$ locus, sources of samples and agr locus in S. aureus isolates was evaluated by the Chi-square test and T-test. Statistical significance was set as a p-value of $\leq 0.05$.

\section{Results}

\section{Prevalence of clinical isolates}

Totally, 1009 clinical samples were collected from patients in Hamedan (Group 1) and Sistan and baluchistan (Group 2). 160 isolates were collected from Group 1 and 190 isolates were collected from Group 2. In Group 1, the most prevalent isolates were collected from blood 58 (36.25\%). Also, in Group 2; most of the samples were isolated from wound 61 (31.10\%) (Fig. 1).

\section{Antibiotic resistance profiles and MIC}

In Group 1, the most prevalent resistance was detected to penicillin $(129,80.62 \%)$ and to chloramphenicol (97 isolates, $60.62 \%)$. In addition, according to the results of of E-test strips, 2 (1.2\%) isolates intermediate-resistance to vancomycin $\geq 3 \mu / \mathrm{ml}, 59(36.87 \%)$ isolates resistant to oxacillin $\geq 4 \mu / \mathrm{ml}$ and 61 isolates $(38.12 \%)$ resistant to cefoxitin $\geq 8 \mu / \mathrm{ml}$ were identified. Also, 61 (38.12\%) MRSA strains were isolated from the clinical and screening samples.

In Group 2, penicillin and ciprofloxacin indicated as the highest resistance, $88.94 \%$ (169) and 63.68\% (121) isolates, respectively. Moreover, based on the results of E-test strips, 4 (2.1\%) isolates showed intermediateresistance to vancomycin $\geq 3 \mu / \mathrm{ml}, 98(51.50 \%)$ isolates resistant to oxacillin $\geq 4 \mu / \mathrm{ml}$ and 99 isolates $(52.10 \%)$ isolates resistant to cefoxitin $\geq 8 \mu / \mathrm{ml}$ were identified. Also, 99 (52.10\%) MRSA strains were isolated from the clinical and screening samples.

In Group 1, most of the MRSA samples were isolated from blood $66.66 \%$ (26 isolates) and wound $55.17 \%$ [32]. Whereas $0 \%$ (0 isolates) and $16.66 \%$ [1] of MSSA strains were detected in aspiration and sputum respectively. In Group 2, the most prevalent MRSA isolates were detected in blood 72.13\% (44) and wound 46.34\% [19], whereas MSSA isolates were identified in aspiration 26.66\% [4] and sputum 10\% [9] respectively, Table 1.

\section{Superantigens genes profiles}

Out of 190 S. aureus isolates of Sistan and baluchistan, 96 (50.5\%) of Zahedan, 30 (15.7\%) of Khash and 64 (33.6\%) isolates of Iranshahr was collected. Also, out of 190 Sistan and baluchistan isolates, seq had the highest frequency and edinB had the lowest frequency,

Table 1 Antimicrobial resistance profiles of MRSA, MSSA, and S. aureus isolates

\begin{tabular}{|c|c|c|c|c|c|c|c|c|c|c|c|c|c|c|c|c|c|c|}
\hline \multirow[t]{3}{*}{ Antibiotics } & \multicolumn{6}{|c|}{ Group1 } & \multicolumn{6}{|c|}{ Group2 } & \multicolumn{6}{|c|}{ S. aureus } \\
\hline & \multicolumn{3}{|c|}{$\begin{array}{l}\text { MRSA }^{a} \\
(n=61)\end{array}$} & \multicolumn{3}{|c|}{$\begin{array}{l}\text { MSSA }^{b} \\
(n=99)\end{array}$} & \multicolumn{3}{|c|}{$\begin{array}{l}\text { MRSA } \\
(n=99)\end{array}$} & \multicolumn{3}{|c|}{$\begin{array}{l}\text { MSSA } \\
(n=91)\end{array}$} & \multicolumn{3}{|c|}{$\begin{array}{l}\text { Group } 1 \\
(n=160)\end{array}$} & \multicolumn{3}{|c|}{$\begin{array}{l}\text { Group } 2 \\
(n=190)\end{array}$} \\
\hline & $\mathbf{R}^{c}$ & $I^{d}$ & $S^{e}$ & $\mathbf{R}$ & I & $\mathrm{S}$ & $\mathbf{R}$ & I & $\mathrm{S}$ & $\mathbf{R}$ & I & $\mathrm{S}$ & $\mathbf{R}$ & I & $\mathrm{S}$ & $\mathbf{R}$ & I & $\mathrm{S}$ \\
\hline Penicillin & 61 & 0 & 0 & 68 & 0 & 31 & 99 & 0 & 0 & 70 & 0 & 21 & 129 & 0 & 31 & 169 & 0 & 21 \\
\hline Tetracycline & 58 & 2 & 1 & 21 & 9 & 69 & 64 & 2 & 33 & 40 & 9 & 42 & 79 & 11 & 70 & 104 & 11 & 75 \\
\hline Clindamycin & 49 & 4 & 8 & 35 & 9 & 55 & 69 & 4 & 26 & 28 & 2 & 61 & 84 & 13 & 63 & 97 & 6 & 87 \\
\hline Gentamicin & 59 & 0 & 2 & 32 & 8 & 59 & 79 & 11 & 9 & 9 & 8 & 74 & 91 & 8 & 61 & 88 & 19 & 83 \\
\hline Ciprofloxacin & 55 & 5 & 1 & 33 & 12 & 54 & 94 & 2 & 3 & 27 & 1 & 63 & 88 & 17 & 55 & 121 & 3 & 66 \\
\hline Erythromycin & 47 & 3 & 11 & 22 & 9 & 71 & 58 & 6 & 35 & 50 & 0 & 41 & 50 & 9 & 82 & 108 & 6 & 76 \\
\hline Chloramphenicol & 57 & 0 & 4 & 40 & 11 & 48 & 83 & 7 & 9 & 15 & 4 & 72 & 97 & 11 & 52 & 98 & 11 & 81 \\
\hline Linezolid & 4 & 0 & 57 & 0 & 0 & 99 & 6 & 0 & 93 & 1 & 0 & 90 & 4 & 0 & 156 & 7 & 0 & 183 \\
\hline $\begin{array}{l}\text { Trimethoprim/sul- } \\
\text { famethoxazole }\end{array}$ & 27 & 3 & 31 & 22 & 1 & 76 & 37 & 6 & 56 & 14 & 3 & 74 & 49 & 4 & 107 & 51 & 9 & 130 \\
\hline Rifampicin & 7 & 0 & 54 & 4 & 0 & 95 & 8 & 0 & 91 & 1 & 0 & 90 & 11 & 0 & 149 & 9 & 0 & 181 \\
\hline \multicolumn{19}{|l|}{$\mathrm{MIC}(\mu \mathrm{g} / \mathrm{ml})$} \\
\hline Vancomycin & 0 & 2 & 59 & 0 & 0 & 99 & 0 & 4 & 95 & 0 & 0 & 91 & 0 & 2 & 158 & 0 & 4 & 186 \\
\hline Oxacillin & 59 & 2 & 0 & 0 & 0 & 99 & 98 & 1 & 0 & 0 & 0 & 91 & 59 & 9 & 92 & 98 & 4 & 88 \\
\hline Cefoxitin & 61 & 0 & 0 & 0 & 0 & 99 & 99 & 0 & 0 & 0 & 0 & 91 & 61 & 11 & 88 & 99 & 5 & 86 \\
\hline
\end{tabular}


Table 2 Prevalence of SAgs genes in S. aureus isolates from patients of Group 1 and Group 2

\begin{tabular}{|c|c|c|c|c|c|c|c|c|c|c|}
\hline \multirow[t]{2}{*}{ SAgs and toxins } & \multicolumn{2}{|c|}{$\begin{array}{l}\text { Group } 1 \\
(n=160)\end{array}$} & \multicolumn{2}{|c|}{$\begin{array}{l}\text { Group 2 } \\
(n=190)\end{array}$} & \multicolumn{2}{|l|}{ MRSA } & \multicolumn{2}{|l|}{ MSSA } & \multirow[t]{2}{*}{$\begin{array}{l}\text { Total } \\
\text { in Group } 1\end{array}$} & \multirow{2}{*}{$\begin{array}{l}\text { Total } \\
\text { in Group } \\
2\end{array}$} \\
\hline & Female & Male & Female & Male & Group 1 & Group 2 & Group 1 & Group 2 & & \\
\hline SEA & 5 & 12 & 11 & 14 & 11 & 20 & 6 & 6 & 17 & 26 \\
\hline SEB & 1 & 10 & 9 & 10 & 7 & 11 & 4 & 8 & 11 & 19 \\
\hline SEC & 3 & 2 & 5 & 16 & 6 & 19 & 0 & 2 & 5 & 21 \\
\hline SED & 11 & 2 & 1 & 16 & 9 & 13 & 4 & 7 & 13 & 17 \\
\hline SEE & 4 & 11 & 6 & 13 & 6 & 16 & 9 & 3 & 15 & 19 \\
\hline SEI-G & 0 & 2 & 8 & 8 & 2 & 11 & 0 & 5 & 2 & 16 \\
\hline SEI-H & 1 & 5 & 3 & 13 & 5 & 9 & 1 & 7 & 6 & 16 \\
\hline SEI & 4 & 3 & 7 & 13 & 6 & 15 & 1 & 5 & 7 & 20 \\
\hline SEl-J & 5 & 6 & 2 & 9 & 7 & 16 & 4 & 2 & 11 & 14 \\
\hline SEI-K & 1 & 6 & 1 & 6 & 6 & 11 & 1 & 2 & 7 & 13 \\
\hline SEI-L & 4 & 5 & 2 & 7 & 4 & 19 & 5 & 2 & 9 & 21 \\
\hline SEI-M & 2 & 9 & 5 & 6 & 10 & 17 & 1 & 9 & 11 & 26 \\
\hline SEI-N & 5 & 7 & 5 & 7 & 9 & 11 & 3 & 8 & 12 & 19 \\
\hline SEI-O & 9 & 13 & 7 & 15 & 16 & 23 & 6 & 6 & 22 & 29 \\
\hline SEI-Q & 8 & 13 & 9 & 12 & 19 & 17 & 2 & 2 & 21 & 19 \\
\hline TSST-1 & 0 & 1 & 4 & 10 & 1 & 9 & 0 & 5 & 1 & 14 \\
\hline etA & 0 & 0 & 3 & 8 & 0 & 9 & 0 & 3 & 0 & 11 \\
\hline$e t B$ & 0 & 0 & 3 & 6 & 0 & 8 & 0 & 1 & 0 & 9 \\
\hline lukS-PVL & 0 & 2 & 2 & 4 & 2 & 5 & 0 & 3 & 2 & 8 \\
\hline lukF-PV & 0 & 0 & 3 & 8 & 0 & 5 & 0 & 6 & 0 & 11 \\
\hline lukE-lukD & 0 & 0 & 2 & 4 & 0 & 6 & 0 & 0 & 0 & 6 \\
\hline edinA & 1 & 0 & 0 & 0 & 1 & 0 & 0 & 0 & 0 & 0 \\
\hline$e \operatorname{din} B$ & 0 & 0 & 0 & 0 & 0 & 0 & 0 & 0 & 0 & 0 \\
\hline edinC & 1 & 0 & 0 & 0 & 1 & 0 & 0 & 0 & 0 & 0 \\
\hline mecA & 49 & 12 & 67 & 32 & 61 & 99 & 0 & 0 & 61 & 99 \\
\hline
\end{tabular}

which were positive in $29(15.2 \%)$ and $3(1.5 \%)$ isolates, respectively. Moreover, out of $160 \mathrm{~S}$. aureus isolates of Hamedan, the seq gene found in $22(13.75 \%)$ isolates was more abundant. None of the isolates of $S$. aureus isolated from Hamadan had etD, etA, etB, lukF-PV and $l u k E-l u k D$ genes. The prevalence of SAgs in female patients was higher than male patients. In addition, MDR strains also had the highest frequency of SAgs genes, Table 2.

\section{agr typing}

In Group 1 out of 160 isolates of S. aureus, 104 (65\%) agr positive and 56 (35\%) agr negative were detected. The frequency of agr locus was identified as 27 (25.96\%) agrA, 49 (47.11\%) isolates agrB, 17 (16.34\%) agrC and 11 (10.57\%) agrD. In Group 2, among 190 isolates of S. aureus, 132 (69.47\%) were positive for $a g r$ and 58 (30.52\%) negative for $a g r$. Also, the frequency of $a g r$ locus was detected as follows: agrA in 39 (29.54\%) agrB in 55 (41.66\%), agrC in $29(21.96 \%)$ and $\operatorname{agrD}$ in 9 (6.81.96\%), Additional file 1: Tables S1, S2.

\section{Statistical analysis}

In this study, using $\mathrm{t}$-test and $\mathrm{Chi}^{2}$, there was a significant relationship between the SAgs and agr locus frequency. And also, a significant relationship was found between phenotypic antibiotic resistance and $m e c A$.

\section{Discussion}

Staphylococcus aureus as a threatening agent in hospitals and societies has a diverse range of strategies including antibiotic resistance, virulence factors and precise regulatory systems which accurately control and synchronize pathogenicity [15]. Therefore, in order to find the relationship among agr types, superantigens production and resistance in MRSA strains, we investigated clinical isolates collected from two different regions of Iran, Hamadan (Group 1) and Sistan and Baluchistan (Group 2).

Among 160 isolates of Group 1 and 190 isolates of Group 2, agrII was the most prevalent type. Strains with agr typeII indicated the highest superantigens production in both groups $(\mathrm{p}<0.05)$. SEl-Q, SEl-O and SEB showed the highest prevalence in Group 1 whereas in Group 2 
SEl-O and SEA were observed as the most widespread ones. Also, TSST-1, exfoliative toxins and pantone valentine toxins were detected only in Group 2. As a common feature between both groups, superantigen production is more prevalent in MRSA strains than MSSA ones $(\mathrm{p}<0.05)$.

Regarding to the different frequency of antibiotic resistant and pathogenic strains in Groups 1 and 2, it is suggested that different climate conditions may cause extensive changes in resistance and pathogenicity of the bacterium. As MacFadden et al. [16], Singer et al. [17], and Kurenbach et al. [18] studies prove this notion, differences in the patterns of climate can lead to widespread changes in antibiotic resistance patterns. Consistent with our results, Zhang et al. [19] demonstrated the effects of various environmental conditions on antibiotic resistance and virulence factors in bacteria. Agr typing as a convenient virulence typing method could contribute to a more precise understanding of the pathogenesis and epidemiology of staphylococcal infections [20]. Consistent with Collery, Nowrouzian and Chini, superantigen production in S. aureus is directly correlated to agr type of isolates. In so-called studies, the most prevalent superantigens were observed in agr types I and III, while in our study agrII was the predominant one [21-24]. To explain, clonal differences of strains collected from different regions should be regarded. Based on Guijarro and khelissa studies, environmental clues influences on evolution processes of the organisms and consequently variety in characteristics of strains occurs [25-27]. Moreover, in MRSA strains $m e c A$ gene leads to some changes in virulence factors of the organism [28]. The activity of this gene affects some structural proteins such as $a g r$, and $a g r$-regulated SAgs such as TSST-1 and SEs, ETs and PVL are influenced [13]. As it is demonstrated in this study, there was a significant association between MRSA prevalence and superantigen production and interestingly superantigens which are regulated by agr system were predominated in Group 2. To illustrate, based on many studies, there is a direct relationship between presence of the $m e c A$ gene and the bacterial phenotypic resistance [29-31]. Studies by Vitali et al. [32], Duran et al. [33] have shown that the presence of the mecA gene could affect Staphylococcus aureus strains in terms of antibiotic resistance patterns. The results of antimicrobial resistance studies conducted in Group 2 were shown a high prevalence of resistance to antibiotics. Although multi-drug resistance strains were detected in both groups, MDR strains predominated in Group 2. As well, vancomycin intermediate S. aureus (VISA) strains in Group 2 were observed more than Group 1. Several factors could be involved in this difference containing age, gender, climatic conditions, food type and regional culture. According to Lundgren et al. [34], Norris et al. [35] and Wushouer et al. [36] which concluded that, cultural factor is one of the most important causes of antibiotic resistance. Consistent with the above mentioned studies, patients in Group 2 were more interested in taking different drugs, and patients in Group 1 showed less willingness to take medication.

In conclusion: a significant relationship between the SAgs frequency and agr locus in both groups has been indicated. Also, a substantial relevance has been found among phenotypic antibiotic resistance and $m e c A$ gene $(\mathrm{p}<0.05)$. The production of superantigens in $S$. aureus plays an important role in the classification of $a g r$ locus, and this locus can affect differently in methicillin-resistant strains.

\section{Limitations}

The results of this study suggest that the activity of various promoters and operons (PII, PIII and egc operon) in $S$. aureus is directly related to agr locus. It seems that SAgs play a role as checkpoints of dissemination. In the current study, collaboration of antibiotic resistance with superantigen production has been proved $(\mathrm{p}<0.05)$. However, the accurate mechanism of such a relationship should be unraveled.

\section{Additional file}

Additional file 1: Table S1. Characteristics of the agr allelic profiles of Group 1 S. aureus. Table S2. Characteristics of the agr allelic profiles of Group 2 S. aureus.

\section{Abbreviations}

agr: accessory gene regulator; MRSA: methicillin resistant S. aureus; SAgs: superantigens; PBP2A: penicillin binding protein; SCCmec: the staphylococcal chromosomal cassette; VISA: vancomycin intermediate-level resistant; VRSA: vancomycin resistant isolates; PVL: Panton-Valentine leukocidin; TSST-1: toxic shock syndrome toxin-1; MGEs: mobile generic elements; CLSI: Clinical Laboratory Standards Institute.

\section{Authors' contributions}

HT and SD performed microbiological and molecular tests and write the manuscript. MA supervised all of the stages of designing the study, conducting the research and writing the manuscript. All authors read and approved the manuscript.

\section{Author details}

${ }^{1}$ Microbiology Department, School of Medicine, Zahedan University of Medical Sciences, Zahedan, Iran. ${ }^{2}$ Microbiology Department, Faculty of Medicine, Hamadan University of Medical Sciences, Pajoohesh Junction, Hamadan, Iran. ${ }^{3}$ Department of Microbiology, School of Medicine, University of Hamadan, Hamadan, Iran. ${ }^{4}$ Brucellosis Research Center, Hamadan University of Medical Sciences, Hamadan, Iran.

\section{Acknowledgements}

The authors of this article are grateful to Hamadan University of Medical Sciences for their financial support in conducting the research.

Competing interests

The authors declare that they have no competing interests. 


\section{Availability of data and materials}

All the data supporting the findings is contained within the manuscript.

\section{Consent for publication}

Not applicable.

\section{Ethics approval and consent to participate}

This study was approved by the Ethics Committee of Hamadan University of Medical Sciences (Code No: IR.UMSHA.REC.1395.757).

\section{Funding}

This Article was conducted on financial support of vice- chancellor for research of Hamadan University of Medical Sciences. The role of the funding was to supply the acquisition of the necessary materials for the research. There isn't any funding in the design of the study and collection, analysis, and interpretation of data and in writing the manuscript.

\section{Publisher's Note}

Springer Nature remains neutral with regard to jurisdictional claims in published maps and institutional affiliations.

Received: 17 December 2018 Accepted: 6 March 2019

Published online: 12 March 2019

\section{References}

1. Mino MJ, Ortiz RT, Randad P, Moffatt LT, Jordan MH, Shupp JW. Localization of superantigen virulence factors in kidney tissue of animals with Staphylococcus aureus-infected burn wounds. J Burn Care Res. 2013;34(1):142-50.

2. Vafaee Mehr M, Alikhani M, Tahmasebi H, Arabestani M. Identification and determination of the relationship between ccr alleles and antibiotic resistance in clinical isolates of methicillin resistant Staphylococcus aureus. J Babol Univ Med Sci. 2017;19(12):28-35.

3. Gardete S, Tomasz A. Mechanisms of vancomycin resistance in Staphylococcus aureus. J Clin Invest. 2014;124(7):2836-40.

4. Fleer A, Hemels MA, Paauw A, Krediet TG. Reduced expression of PBP-2A by neonatal mecA-positive coagulase-negative staphylococci (CoNS) blood isolates: beta-lactams are useful first-line agents for the treatment of neonatal CoNS sepsis, restricting the use of vancomycin. J Antimicrob Chemother. 2012;67(7):1616-8.

5. Tahmasebi H, Zeiyni B, Dehbashi S, Motamedi H, Vafaeifar M, Keramat F, et al. The study of blaZ and mecA gene expression in methicillin-resistant Staphylococcus aureus strains and the relationship between the gene expression patterns. J Isfahan Med Sch. 2017;35(443):1062-7.

6. Deodhar D, Varghese G, Balaji V, John J, Rebekah G, Janardhanan J, et al. Prevalence of toxin genes among the clinical isolates of Staphylococcus aureus and its clinical impact. J Glob Infect Dis. 2015;7(3):97-102.

7. Solanki LS, Srivastava N, Singh S. Superantigens: a brief review with special emphasis on dermatologic diseases. Dermatol Online J. 2008;14(2):3

8. Tuffs SW, James DBA, Bestebroer J, Richards AC, Goncheva MI, O'Shea M, et al. The Staphylococcus aureus superantigen SEIX is a bifunctional toxin that inhibits neutrophil function. PLoS Pathog. 2017;13(9):e1006461.

9. Dehbashi S, Tahmasebi H, Zeyni B, Arabestani M. The relationship between promoter-dependent quorum sensing induced genes and methicillin resistance in clinical strains of Staphylococcus aureus. J Zanjan Univ Med Sci. 2018;26(116):75-87.

10. Beceiro A, Tomás M, Bou G. Antimicrobial resistance and virulence: a successful or deleterious association in the bacterial world? Clin Microbiol Rev. 2013;26(2):185-230.

11. Bokaeian M, Tahmasebi H. Molecular identification of genes responsible for resistance to aminoglycosides and methicillin in clinical samples of Staphylococcus aureus. J Babol Univ Med Sci. 2017;19(3):38-46.

12. Schlievert PM, Case LC, Strandberg KL, Tripp TJ, Lin Y-C, Peterson ML. Vaginal Staphylococcus aureus superantigen profile shift from 1980 and 1981 to 2003, 2004, and 2005. J Clin Microbiol. 2007;45(8):2704-7.

13. Jarraud S, Mougel C, Thioulouse J, Lina G, Meugnier H, Forey F, et al. Relationships between Staphylococcus aureus genetic background, virulence factors, agr groups (alleles), and human disease. Infect Immun. 2002;70(2):631-41.

14. Soares BS, Melo DA, Motta CC, Marques VF, Barreto NB, Coelho SMO, et al. Characterization of virulence and antibiotic profile and agr typing of Staphylococcus aureus from milk of subclinical mastitis bovine in State of Rio de Janeiro. Arquivo Brasileiro de Medicina Veterinária e Zootecnia. 2017;69:843-50.

15. Thompson TA, Brown PD. Association between the agr locus and the presence of virulence genes and pathogenesis in Staphylococcus aureus using a Caenorhabditis elegans model. Int J Infect Dis. 2017;54:72-6.

16. MacFadden DR, McGough SF, Fisman D, Santillana M, Brownstein JS Antibiotic resistance increases with local temperature. Nat Clim Change. 2018:8(6):510-4.

17. Singer AC, Shaw $H$, Rhodes $V$, Hart A. Review of antimicrobial resistance in the environment and its relevance to environmental regulators. Front Microbiol. 2016;7:1728

18. Kurenbach B, Hill AM, Godsoe W, van Hamelsveld S, Heinemann JA. Agrichemicals and antibiotics in combination increase antibiotic resistance evolution. PeerJ. 2018;6:e5801.

19. Zhang $L$, Rogers TJ. Assessment of the functional regions of the superantigen staphylococcal enterotoxin B. Toxins. 2013;5(10):1859-71.

20. Mullarky IK, Su C, Frieze N, Park YH, Sordillo LM. Staphylococcus aureus agr genotypes with enterotoxin production capabilities can resist neutrophil bactericidal activity. Infect Immun. 2001;69(1):45-51.

21. Collery MM, Smyth DS, Tumilty JJ, Twohig JM, Smyth CJ. Associations between enterotoxin gene cluster types egc1, egc2 and egc3, agr types, enterotoxin and enterotoxin-like gene profiles, and molecular typing characteristics of human nasal carriage and animal isolates of Staphylococcus aureus. J Med Microbiol. 2009;58(Pt 1):13-25.

22. Collery MM, Smyth DS, Twohig JM, Shore AC, Coleman DC, Smyth CJ. Molecular typing of nasal carriage isolates of Staphylococcus aureus from an Irish university student population based on toxin gene PCR, agr locus types and multiple locus, variable number tandem repeat analysis. J Med Microbiol. 2008;57(Pt 3):348-58.

23. Nowrouzian FL, Dauwalder O, Meugnier H, Bes M, Etienne J, Vandenesch F, et al. Adhesin and superantigen genes and the capacity of Staphylococcus aureus to colonize the infantile gut. J Infect Dis. 2011;204(5):714-21.

24. Chini V, Dimitracopoulos G, Spiliopoulou I. Occurrence of the enterotoxin gene cluster and the toxic shock syndrome toxin 1 gene among clinical isolates of methicillin-resistant Staphylococcus aureus is related to clonal type and agr group. J Clin Microbiol. 2006;44(5):1881-3.

25. Guijarro JA, Cascales D, García-Torrico Al, García-Domínguez M, Méndez J. Temperature-dependent expression of virulence genes in fish-pathogenic bacteria. Front Microbiol. 2015;6:700.

26. Khelissa SO, Jama C, Abdallah M, Boukherroub R, Faille C, Chihib N-E. Effect of incubation duration, growth temperature, and abiotic surface type on cell surface properties, adhesion and pathogenicity of biofilmdetached Staphylococcus aureus cells. AMB Express. 2017;7:191.

27. Corredor Arias LF, Luligo Espinal JS, Moncayo Ortiz Jl, Santacruz Ibarra JJ, Álvarez Aldana A. Relationship between super antigenicity, antimicrobial resistance and origin of Staphylococcus aureus isolated. Colomb Med. 2016;47(1):15-20.

28. Suryadevara M, Clark AE, Wolk DM, Carman A, Rosenbaum PF, Shaw J. Molecular characterization of invasive Staphylococcus aureus infection in central New york children: importance of two clonal groups and inconsistent presence of selected virulence determinants. J Pediatr Infect Dis Soc. 2013;2(1):30-9.

29. Otarigho B, Falade MO. Analysis of antibiotics resistant genes in different strains of Staphylococcus aureus. Bioinformation. 2018;14(3):113-22.

30. Yilmaz S, Kilic A, Karagoz A, Bedir O, Uskudar Guclu A, Basustaoglu $A C$. Investigation of various virulence factors among the hospital and community-acquired Staphylococcus aureus isolates by real-time PCR method. Mikrobiyol Bul. 2012;46(4):532-45.

31. Cameron DR, Howden BP, Peleg AY. The interface between antibiotic resistance and virulence in Staphylococcus aureus and its impact upon clinical outcomes. Clin Infect Dis. 2011;53(6):576-82.

32. Vitali LA, Petrelli D, Lamikanra A, Prenna M, Akinkunmi EO. Diversity of antibiotic resistance genes and staphylococcal cassette chromosome mec elements in faecal isolates of coagulase-negative staphylococci from Nigeria. BMC Microbiol. 2014;14(1):106. 
33. Duran N, Ozer B, Duran GG, Onlen Y, Demir C. Antibiotic resistance genes \& susceptibility patterns in staphylococci. Indian J Med Res. 2012;135(3):389-96

34. Touboul-Lundgren P, Jensen S, Drai J, Lindbæk M. Identification of cultural determinants of antibiotic use cited in primary care in Europe: a mixed research synthesis study of integrated design "Culture is all around us". BMC Public Health. 2015;15:908.
35. Norris P, Chamberlain K, Dew K, Gabe J, Hodgetts D, Madden H. Public beliefs about antibiotics, infection and resistance: a qualitative study. Antibiotics. 2013;2(4):465-76.

36. Wushouer H, Zhang ZX, Wang JH, Ji P, Zhu QF, Aishan R, et al. Trends and relationship between antimicrobial resistance and antibiotic use in Xinjiang Uyghur Autonomous Region, China: based on a 3 year surveillance data, 2014-2016. J Infect Public Health. 2018;11(3):339-46.
Ready to submit your research? Choose BMC and benefit from:

- fast, convenient online submission

- thorough peer review by experienced researchers in your field

- rapid publication on acceptance

- support for research data, including large and complex data types

- gold Open Access which fosters wider collaboration and increased citations

- maximum visibility for your research: over $100 \mathrm{M}$ website views per year

At BMC, research is always in progress.

Learn more biomedcentral.com/submissions 